\title{
Chaplaincy Documentation in a Large US Health System
}

\author{
Brent Peery
}

Chaplaincy documentation practices in the United States have evolved over time. Variation in practice still remains. However, the trend in the profession is toward the expectation that chaplains will document their care. There is also increased expectation regarding the content of that documentation. Demonstrating competency in clear and effective documentation is required for board certification and is identified among the expected standards of practice for the profession (Association for Clinical Pastoral Education et al. 2016; Association of Professional Chaplains Quality Committee 2015).

I have been writing and teaching on the subject since 2008. The content of this paper was developed in response to consistently strong energy, interest, and concern I have experienced from professional chaplains on the subject for the last decade. This growing interest seems to be driven by increased concern for the spiritual needs of patients and families within healthcare paired with the large number of healthcare organizations shifting to electronic medical records (EMRs). Though I have given this topic considerable thought, research, and practice, I do not pretend to have all the answers.

In this paper, I will share a little of the history and current practice of chaplaincy documentation within the Memorial Hermann Health System. This will include a discussion of the who, what, where, when, how, and why of chaplaincy documentation. Like many other chaplaincy departments, but by no means all, we take our documentation seriously. We try to document our care in a manner that bears witness to the holistic humanity of our care recipients. We also want to describe our care in a way that helps others understand the important ways professional chaplains contribute to the well-being of others.

\footnotetext{
B. Peery $(\square)$

Memorial Hermann Health System, Houston, TX, USA
} 


\section{History}

The Memorial Hospital System originated in 1907, and the Hermann Hospital was opened in 1925. The two merged in 1997 to become the Memorial Hermann Health System. As of this writing, Memorial Hermann is comprised of 15 acute care hospitals, 2 physical rehab hospitals, 1 addiction treatment hospital, 1 hospice, 1 retirement home, and over 250 outpatient facilities in Houston, Texas, and the surrounding area. We have 42 professional chaplains, 11 chaplain residents, 5 administrative professionals, and 42 PRN (as needed) chaplains who serve in these entities. I have worked at Memorial Hermann for over 17 years as a chaplain resident, staff chaplain, chaplain manager, chaplain director, and currently as the vice president for chaplaincy.

I have spent my entire chaplaincy career in a setting where chaplaincy documentation has been ahead of the curve of national trends. Both professional chaplains and chaplain residents have documented their care in patients' medical records at Memorial Hermann and its predecessor organizations for over 45 years. With regard to this task, we are treated like any other healthcare professional on the interdisciplinary healthcare team. Chaplains documented exclusively in paper charts back in the 1970s and 1980s. Chaplains wrote in ink about their care in the patient's chart, which generally consisted of forms hole-punched and collated in a plastic binder. However, beginning in the late 1980s, Memorial Hermann began the slow transition to EMR. For over fifteen years we have almost exclusively documented our care in the EMR. Memorial Hermann's chaplains are required by current organizational policy to document their care for patients and families in our EMR software.

As a continuation of our emphasis on outcome-oriented chaplaincy ${ }^{1}$ (OOC), which began in 2005, during 2006 and 2007, the professional chaplains of Memorial Hermann developed a uniform structure for chaplaincy documentation. Before that time, there was great variation in what Memorial Hermann chaplains documented about the care we provided. We came to believe a consistent approach to documentation across our system might help us be more intentional about our work and therefore improve our care. We also thought it would help other healthcare professionals understand better and potentially appreciate our work more. We reviewed the published literature on chaplaincy documentation at that time. In addition, we contacted a variety of hospitals throughout the United States to educate ourselves on existing chaplaincy charting practice. Then, we reviewed various models and discussed for months what we thought would be best documentation practice for us as chaplains. We finally identified what came to be called the Memorial Hermann Chaplaincy Documentation Model. It consisted of five parts:

(1) Reason for visit (Why is the chaplain involved?)

\footnotetext{
1 "[Outcome-oriented chaplaincy] is a method of chaplaincy care that emphasizes achieving, describing, measuring, and improving outcomes that result from a chaplain's work. Its primary components include chaplaincy assessment, chaplaincy interventions, and chaplaincy outcomes" (Peery 2012a, b, 343).
} 
(2) Interventions (What did the chaplain do to help the care recipient?)

(3) Outcomes (How did the care recipient respond? What difference did the chaplain's interventions make?)

(4) Assessment (How would the chaplain summarize this care recipient's current spiritual/emotional/relational state to the rest of the interdisciplinary healthcare team?)

(5) Plan (What does the chaplain intend to do further or recommend to the interdisciplinary healthcare team? $)^{2}$

In the years since, many other professional chaplains from around the United States have adopted or adapted the Memorial Hermann Chaplaincy Documentation Model for their own practice.

In 2008, we designed and built a custom chaplaincy documentation template into our EMR software, based on our model. In 2013, we revised and expanded the content of our electronic template. The resulting new template was built into the software in 2014.

I learned some lessons from the experience of building and redesigning these templates. I share them here for those chaplains who may engage in a similar process. The first lesson I learned was to know or learn what your priorities are in this project. This will help you communicate clearly with the technical professionals with whom you will likely collaborate to build a custom documentation template.

Our task force identified four priorities in the most recent redesign of our template. The first priority was the ease of use of the template for entering data. We wanted to make it as easy as possible for chaplains to clearly document their care, in recognition of heavy workloads. The second priority was the clarity of the resulting chart notes. We wanted the data output to be clear to others who would read our notes. Our third priority was we wanted the template to be useful for chaplaincy education. We wanted the template to contribute to an action-reflection-action model of professional development. We designed it to help chaplains think through the content and efficacy of their work. A key part of this is the inclusion of extensive pre-supplied content. We envisioned this to be a design feature of particular value to chaplain residents and inexperienced chaplains. We also envisioned a template that helped other healthcare professionals more thoroughly understand the care provided by professional chaplains. Our final major priority was to build a template with the potential to use it to extract data for future research about our work. We had already tried and failed to get help in extracting modest data from our previous template. However, we were optimistic that the day would come when we could get that sort of analytics help. We wanted our template to be ready when the time came. The volume of pre-supplied content also contributed to this priority.

Another lesson I learned from our template design and build process was to know or learn your limitations. In our process, we encountered both software and institutional limitations. We had to make some compromises on our ideal design because

${ }^{2}$ Cf. Peery 2008. A mnemonic phrase was developed to help remember the model: "Run In On A Prayer." 
the software was not able to do what we preferred. We also encountered limitations because our institution had limited resources they could allocate to help us with our build. Despite those limitations that prevented us from getting everything we wanted, the end product of our most recent template has proven to be a valuable tool in our work for over five years.

Value the process was the final major lesson learned in our two documentation template designs and builds. From start to finish, each took about twelve to fifteen months. We work in a large organization and change can take a while. Along the way, we saw benefit in each of these from our discussions with each other about our work and how we describe that work to others. We debated about the wording of interventions and outcomes. We dialogued about our assessment process and descriptions. I think those discussions helped us to be better chaplains, apart from any product they produced.

\section{General Guidelines}

\subsection{Who Reads Our Documentation?}

There are a variety of persons who could potentially read our documentation. Most will fall into one of the following groups. These are listed in the order of likelihood to read according to our experience:

(1) Other chaplains - As a part of our chaplaincy assessment and care, we read other chaplains' documentation who have previously provided care to a patient/ family and incorporate their insights.

(2) Other healthcare professionals - Nurses, physicians, social workers, and many other professionals utilize our expertise as recorded in our documentation to inform their own care for a patient/family.

(3) The patient and/or family - The patient has a legal right to obtain a copy of his/ her medical records. The patient, or his/her surrogates, may read our documentation there.

(4) Members of the justice system - Occasionally a copy of a patient's medical record is subpoenaed by representatives of the civil or criminal justice system as part of their work. Chaplains have been asked to give testimony in legal proceedings based on the content of their documentation.

I have found it helpful to imagine representatives from all these groups looking over my shoulder as I document my care. We should document in a manner that communicates appropriately to all of these potential audiences. 


\subsection{What Do We Document?}

There seem to be two broad schools of thought related to chaplaincy documentation. There are those that favor a minimalist approach and those that favor a more comprehensive approach. Because of increasing professionalism within chaplaincy, the minimalist school is shrinking. I have a clear bias toward the comprehensive school.

The minimalist school stresses documenting the bare minimum. A definition of minimal is "of the least possible; minimum or smallest" (Collins English Dictionary). Those who embrace a minimalist approach believe chaplains should document little or nothing. They argue that what we do cannot be described. Minimalists often identify confidentiality as the supreme value for guiding our documentation; documenting little leaves very little risk for violating confidentiality. An example of minimalist documentations would be "Provided chaplaincy care." When sociologist Wendy Cadge studied 19 chaplaincy departments in the United States for her book Paging God: Religion in the Halls of Medicine, she categorized those departments in three groups according to their level of professionalism. She assessed each department as being professional, transitional, or traditional. She identified these minimalist "I was here" chaplaincy documentation notes as characteristic of the traditional (least professional) departments (Cadge 2012, 114-121, 124, 139).

What are some the factors that commonly contribute to minimalist chaplaincy documentation? As was mentioned, a strong fear of violating confidentiality is often an issue. Because of where they trained and have worked, some chaplains never learned anything more than minimal documentation. For others, laziness is a factor. A few chaplains choose a minimalist approach because they resist any form of accountability for their work.

The comprehensive school seeks a more thorough approach to documentation. A definition of comprehensive is "of broad scope or content; including all or much" (Collins English Dictionary). Those who embrace a comprehensive approach believe chaplains should document like other healthcare professionals. Though we acknowledge there are aspects of chaplaincy care that defy description, we affirm that much of what we do can be described. For us, care is the supreme value for guiding our documentation. We are concerned that patients and families receive the best holistic care possible and believe thorough chaplaincy documentation will contribute to that goal. As we will discuss below, a comprehensive approach involves more than minimalist documentation and values concise communication.

The profession is increasingly moving toward a comprehensive approach to chaplaincy documentation. There has been some support for this approach dating back to at least 1940. In that year, Russell Dicks, chaplain at Presbyterian Hospital in Chicago, included detailed documentation in the patient's medical record among minimum recommended standards for chaplaincy (Dicks 1940). Every standards of practice document produced by the Association of Professional Chaplains since 2010 has included a standard for documentation. The most recent one is Standards of Practice for Professional Chaplains. Standard 3 states, "Documentation of Care: 
The chaplain documents in the appropriate recording structure information relevant to the care recipient's well-being" (Association of Professional Chaplains Committee on Quality 2015).

Memorial Hermann chaplains describe our care through the five sections of the Memorial Hermann Chaplaincy Documentation Model: reason for visit, interventions, outcomes, assessment, and plan. Our primary areas of education, skill, and experience are:

(1) Spiritual

(2) Emotional

(3) Relational

Our documentation focuses mostly on these three areas of our professional expertise. Our chart notes should reflect what we assess through our senses - saw, heard, smelt, or felt - and what we did (interventions) related to these aspects of the care recipient's experience.

Because we are committed to holistic interdisciplinary healthcare, we also incorporate knowledge of the patient/family's biomedical needs, hopes, and resources into our care. These issues frequently impact a person's spiritual, emotional, and relational well-being. However, we rely upon other healthcare professionals with greater expertise in those areas to provide biomedical documentation. Chaplains are cautioned to refrain from documenting biomedical content. When referencing biomedical issues relevant to our chaplaincy care, an external source for that information should be documented (i.e., "Per RN's report, pt [patient] received a new diagnosis of diabetes today").

In general, chaplains should refrain from including any hearsay in their documentation. Among other potential reasons, in an effort to make sense of a patient's illness or injury, it is not unusual for first responders, family, healthcare providers, and sometimes the media to tell the story of how the patient came to be hospitalized. Very often early versions of those stories are revised with the passage of time and a more thorough collection of facts. For example, it is not generally appropriate for a chaplain to document "Pt was admitted for a self-inflicted gunshot wound to the head." This would very rarely be information the chaplain knows firsthand.

Important note: The Joint Commission (TJC) is a major accrediting organization for American hospitals. When the TJC does an onsite accreditation survey of a hospital, they do patient medical record "tracers" to evaluate the quality of care provided. These involve reading/tracing a patient's medical record from admission until the present. From a chaplaincy perspective, they expect our notes to tell the story of our care, including our assessment, interventions, and outcomes. Also, of particular concern for them is when any healthcare professional indicates a plan of care for the patient and family. In such cases, they want to see further documentation indicating the plan was implemented. When we indicate in our documentation a plan to follow up, we make sure we do follow up and document that care. 


\subsection{When Do We Document?}

We document after every chaplaincy visit. As the saying around healthcare goes, "If it's not in the chart, it did not happen!" Sometimes we also document after unsuccessful attempts to visit. The latter practice can demonstrate responsiveness to referrals, even though circumstances may have prevented the visit (i.e., patient is away from their room for a procedure). It can also help facilitate communication within multi-staff chaplaincy departments.

It is best practice to document as soon after the visit as is practical. There will be times when demands are so intense that a chaplain is not able to document for a few hours. However, there are some benefits from charting after every visit or two, when possible. First, it yields more accurate notes. After the passage of time and multiple encounters, important details of our care can begin to fade from our minds. Second, it can facilitate chaplain self-care. This can be intense and draining work. The discipline of timely documentation can help the chaplain take a break and clear his/her mind from the previous visit before going on to the next. Third, documenting in the clinical setting between visits can facilitate staff care. It often creates opportunities for informal conversation at the nurses' station that lead to important caring opportunities for other healthcare professionals who need our support.

\subsection{Where Do We Document?}

Memorial Hermann chaplain documentation is recorded in a section of the patient's EMR where notes from other professionals on the interdisciplinary healthcare team also appear. This demonstrates the value of both holistic patient care and the valuable contributions chaplains make to that process.

\subsection{Why Do We Document?}

First and foremost, chaplains document because we are healthcare professionals. Healthcare professionals document their work. This is primarily to promote interdisciplinary communication and teamwork and optimize care. There are also legal and regulatory reasons why healthcare professionals must document their care.

There are other compelling reasons for chaplaincy documentation. We value holistic care for patients and families. Our notes are testimony that the patient is not just a body; he/she is a person with spirituality, thoughts, emotions, and relationships. Our documentation can help other healthcare professionals understand and respond helpfully to patient/family spiritual, emotional, and relational needs, hopes, and resources. Lastly, our documentation can help other healthcare professionals 
better understand chaplaincy care and partner with us more appropriately in caring for patients and families.

\subsection{How Do We Document?}

We document with clarity. Our work and the human beings for whom we care are very complex. However, we endeavor to clearly communicate both in our documentation.

We document with conciseness. As Gordon Hilsman writes, "Nobody reads long chart notes" (Hilsman 2017, 206). Clarity and brevity are related. Art Lucas contended that the ability to describe our work succinctly is evidence of clarity (VandeCreek and Lucas 2001, 19). This is difficult. It is a skill that gets better with practice.

We document with care. Our primary motive for all of our work should be care and concern for the other. This includes the work of documentation. We want to document enough to insure patients and families receive the best possible care. The Golden Rule applies. Document in a manner you would want for yourself or your loved one if the roles were reversed.

We document with confidentiality. "The chaplain respects the confidentiality of information from all sources, including the care recipient, legal, or organizational records, and other care providers in accordance with federal and state laws, regulations, and rules" (Association of Professional Chaplains Committee on Quality 2015, Standard 6, Confidentiality). The relationship between a chaplain and a patient/family is one of sacred trust. Our documentation should be respectful of the trust others give to us. There are, however, limits to confidentiality. In general, those limits are crossed when we learn someone has or will do harm to self or others. In such cases, we need to appropriately disclose such information. We also disclose other information to the patient's treatment team we believe will enhance that patient's care.

On the subject of confidentiality, like other US healthcare professionals, we are subject to patient privacy laws like the Health Insurance Portability and Accountability Act (HIPAA). This law was passed, in part, to make sure healthcare professionals respected the confidentiality of a patient's medical records. When we first access a patient's EMR, we are prompted by the software to identify our relationship with that patient (i.e., chaplain, chaplain resident/intern). We only access the EMR of patients when doing so is necessary for our work. Once in a patient's medical record, we only access the parts of that EMR necessary to provide spiritual, emotional, and relational support to that patient and his/her family. Chaplains should access a patient's EMR with professional integrity and a very high degree of respect for the privacy of those we serve. There is an enduring electronic record of all of our activity within a patient's EMR. 


\section{The MH Chaplaincy Documentation Template}

The Memorial Hermann chaplaincy documentation template is designed to be a tool that helps chaplains clearly describe the care they have provided to patients and families. The Chaplain Visit form consists of five pages, corresponding with the five parts of the MH Chaplaincy Documentation Model (reason for visit, interventions, outcomes, assessment, and plan). On each of the five pages, there are both presupplied (click-to-select) content and free text boxes into which we can type original content. We can use either of these means of entering content or both in combination. MH chaplains may use their judgment and preferences to guide them to the best means to clearly communicate their care (The "What Do We Document?" and "How Do We Document?" sections above provide additional guidance). Other considerations include:

(1) New chaplain residents and interns may want to limit themselves mostly to the click-to-select content for a few weeks until they feel more comfortable and competent with documentation.

(2) The amount of content in our documentation is directly related to the duration and complexity of our chaplaincy care. A relatively brief encounter in which no chaplaincy care needs are assessed would generally yield a short chart note. A longer helping encounter, in which the need for more significant interventions and outcomes is assessed, should result in a more comprehensive chart note.

\subsection{Significant Other (SO) Designation Form}

There is also an optional SO Designation form. This form facilitates identifying SOs related to a particular patient and who are recipients of chaplaincy care. Common SO roles could include husband, wife, boyfriend, girlfriend, domestic partner, father, mother, daughter, son, brother, sister, friend, etc. These roles will be imported into all subsequent Chaplain Visit forms for this patient until a different SO Designation is completed for the patient. These roles can also be edited or entered in the Chaplain Visit form. Therefore, the SO Designation form is optional. It was developed so the chaplain would not have to identify SOs every time they document care to a particular patient/family (Fig. 1).

\subsection{Reason for Visit}

The Reason for Visit page includes a box to indicate the amount of time in minutes (rounded to the nearest 0.25 hours) spent providing chaplaincy care during this encounter. While this information is not directly related to the reason for the visit, it is valuable information to record about our care. Our chaplain design team chose to 


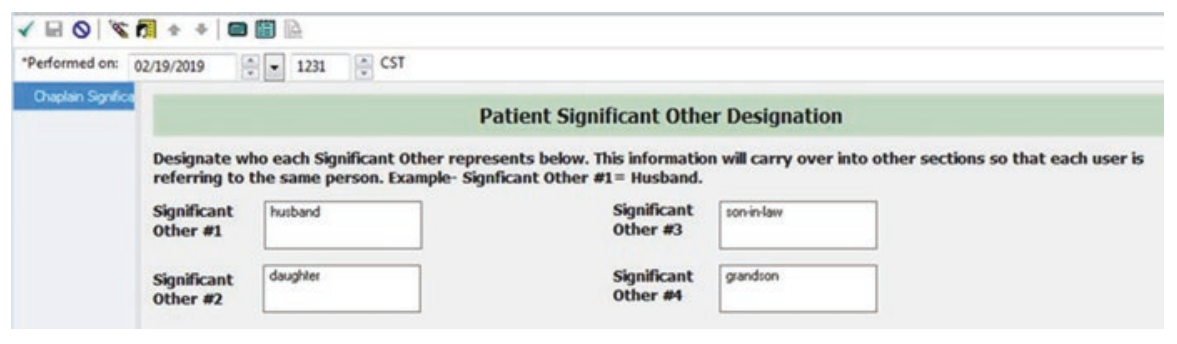

Fig. 1 Significant Other Designation Form. (Reproduced with permission from Memorial Hermann Health System. Copyright $\odot 2013$ Memorial Hermann. All rights reserved)

place the input for this information here because it seemed like the best among the available options. The second box contains several common click-to-select reasons for a chaplaincy visit. Note that selecting the "Referral from" option in the Reason for Visit box opens the third "Referral from" box. This box contains some common sources of referral. (Selecting "Other" in any box enables you to add an option that better communicates.) There is an "Additional Reasons for Visit" free text box into which you can type other information to convey the reason for the chaplaincy encounter. The "Patient Religious Preference" box imports the religious preference identified for the patient at admission. We cannot directly alter this information in the patient's EMR. However, we can confirm it is correct in our assessment. If it is inaccurate, we can contact the admissions department to get the information corrected (Fig. 2).

\subsection{Interventions}

When we expanded the pre-supplied list of common chaplaincy interventions from 34 to 44 interventions during the 2013 revision of this template, we decided to divide the interventions' list into five categories (empowerment, exploration, collaboration, relationship building, and ritual). This was intended to both broadly describe the kinds of interventions we provide and to reduce the length of the list a chaplain reads through when utilizing click-to-select content. All of the content entered on this page is action-oriented. It describes what the chaplain did to help the care recipient. For definitions and examples of each of the listed interventions, see the glossary below (Fig. 3). 


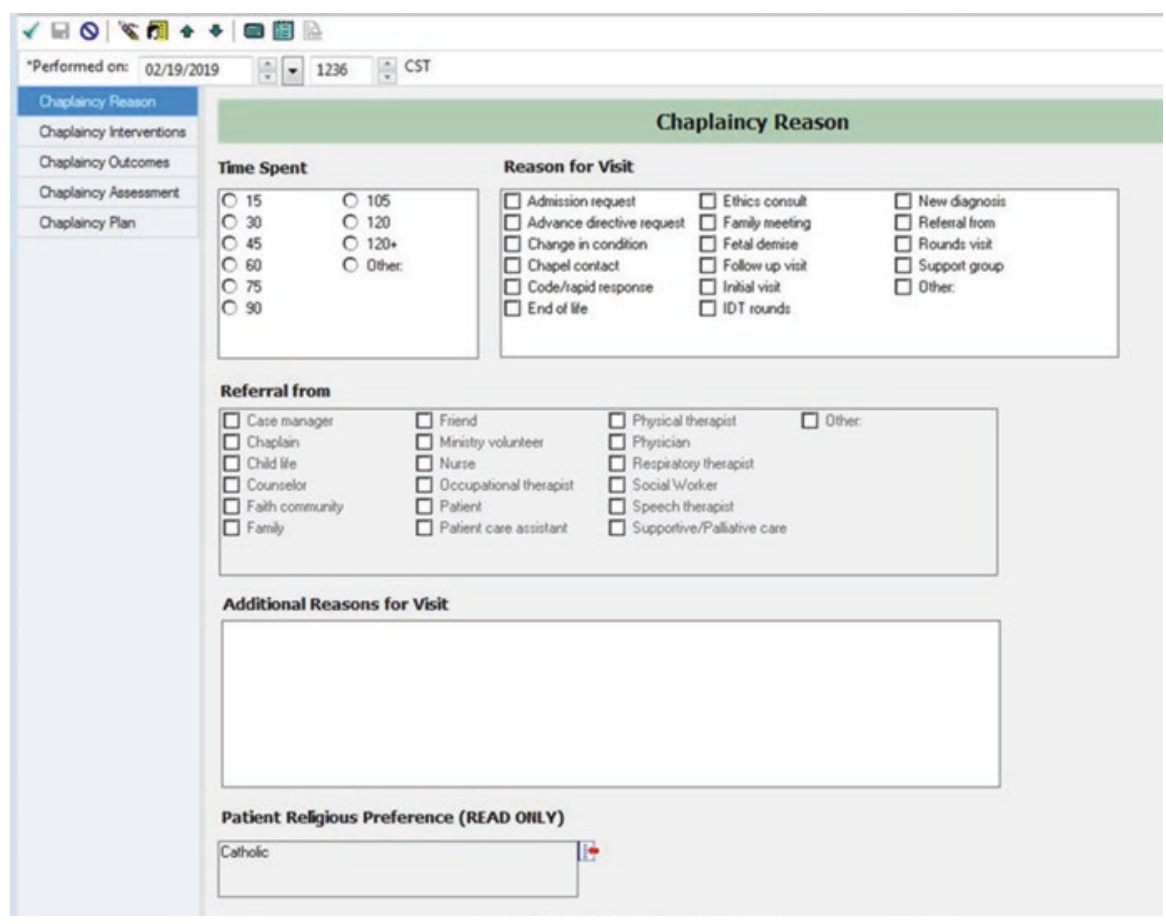

Fig. 2 Reason for Visit Form. (Reproduced with permission from Memorial Hermann Health System. Copyright (c) 2013 Memorial Hermann. All rights reserved)

\subsection{Outcomes}

Art Lucas wrote mostly about outcomes in the future tense, i.e., "desired contributing outcomes" (VandeCreek and Lucas 2001, 18-21). We might also call these "chaplaincy care goals." In our documentation model, we would include goals in the plan section. We use the outcomes section to describe the observable differences our care made for the care recipient during the encounter just completed. As such, they are worded in the past tense. In describing outcomes, we acknowledge there may be significant outcomes that cannot be sensed or described. However, our experience has been that focusing on discernable outcomes helps us evaluate and improve our care. It also helps others better understand our care (For definitions and examples of each of the listed outcomes, see the glossary (Fig. 4)). 


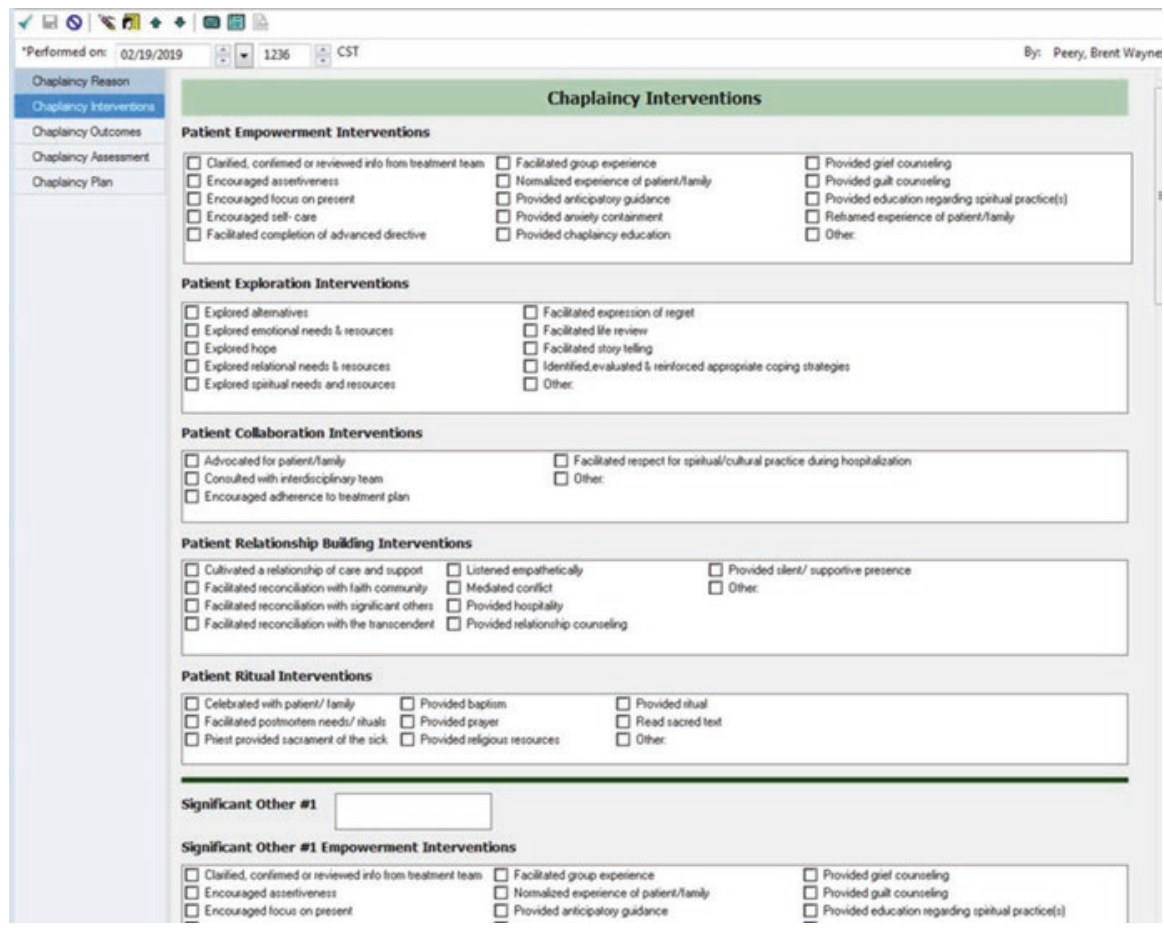

Fig. 3 Chaplaincy Interventions Form. (Reproduced with permission from Memorial Hermann Health System. Copyright @ 2013 Memorial Hermann. All rights reserved)

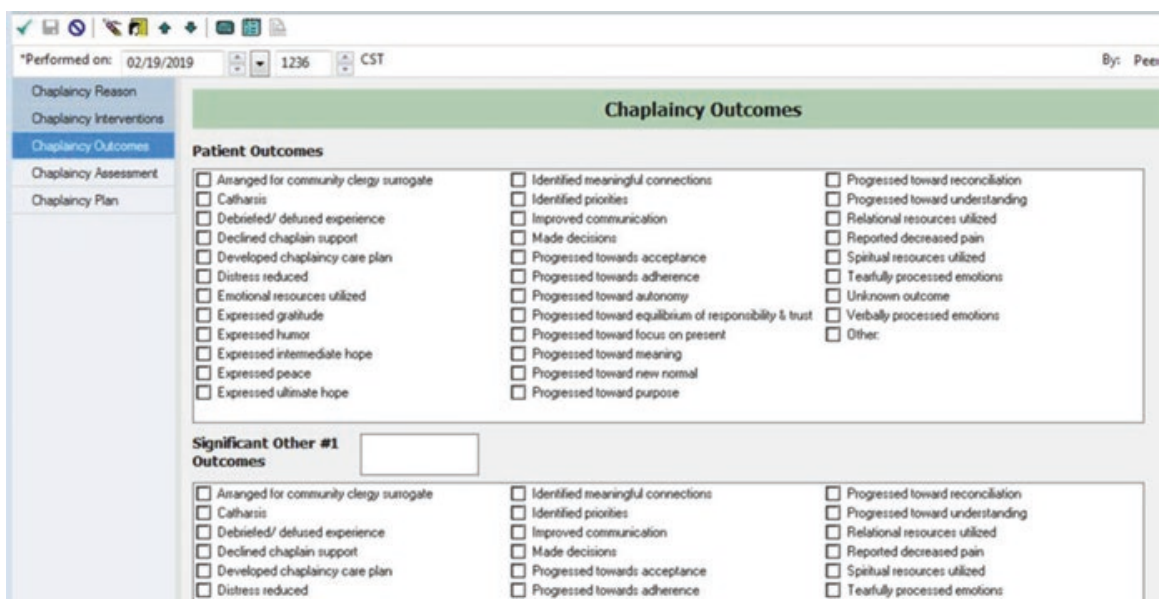

Fig. 4 Chaplaincy Outcomes Form. (Reproduced with permission from Memorial Hermann Health System. Copyright @ 2013 Memorial Hermann. All rights reserved) 


\subsection{Assessment}

Our goal in the assessment section is to succinctly summarize and communicate the current spiritual, emotional, and relational state of the recipients of our care. We are often asked about our documentation model, "Why do you document the assessment after the interventions? Don't you assess before you intervene?" It is true that we often assess before we intervene. However, chaplaincy assessment is more complex than such a simple linear conceptualization would illustrate. Our assessment is a dynamic process. It often begins before we even enter the room with the other. This early assessment work could be based on many factors such as what we were told by a referral source, what we read in the patient's EMR, where the patient is located, etc. We hold those early assessments loosely. As our caring encounters progress, we move fluidly between assessment, interventions, and outcomes. Sometimes early assessments need to be modified or discarded based on additional information. Sometimes the spiritual, emotional, or relational state of the other varies throughout the helping encounter. In light of this complexity, we asked ourselves, "What should we document?" Our answer is reflected in the first sentence in this paragraph. We decided this is the most helpful information to include. Further, we decided this was the best place in the documentation model to communicate it. ${ }^{3}$ The assessment page in our documentation template is built around:

(1) Spiritual needs, hopes, and resources

(2) Emotional needs, hopes, and resources

(3) Relational needs, hopes, and resources

Our emphasis on assessing needs, hopes, and resources is rooted in the work of Art Lucas. He cautioned chaplains against accepting the primary pathological focus of medicine. He warned against the tendency to only see our care recipients in terms of their needs. Lucas encouraged chaplains to also assess the person's hopes and resources (VandeCreek and Lucas 2001, 8).

The "Patient/Significant Other Needs \& Hopes" box (see screenshot below) is known as an ultra-grid in our EMR software. To access the click-to-select content for spiritual, emotional, or relational needs (first three columns), we click on the box under the appropriate heading and to the right of the person we are assessing. This opens a pop-up box with a pre-supplied list of common needs. ${ }^{4}$ Chaplains can select any of the listed common needs assessed with the care recipient or type in any additional identified needs. The right two columns are for typing hopes the care

\footnotetext{
${ }^{3}$ The MH Chaplaincy Documentation Model is a communication strategy. It is not necessarily a chronological retelling of all that occurred in the helping encounter.

${ }^{4}$ These lists include as follows: Spiritual needs - belief issues, guilt, lack of gratitude, lack of meaning, lack of peace, lack of purpose, lack of self-care, misinformation, providence issues, and theodicy issues. Emotional needs - anger, anxiety, betrayal, confusion, despair, fatigue, fear, frustration, grief, loneliness, resentment, sadness, and shame. Relational needs - conflict, lack of assertiveness, lack of autonomy, lack of communication, lack of companionship, lack of relational skills, lack of responsibility, lack of trust, rejection, and unrealistic expectations.
} 


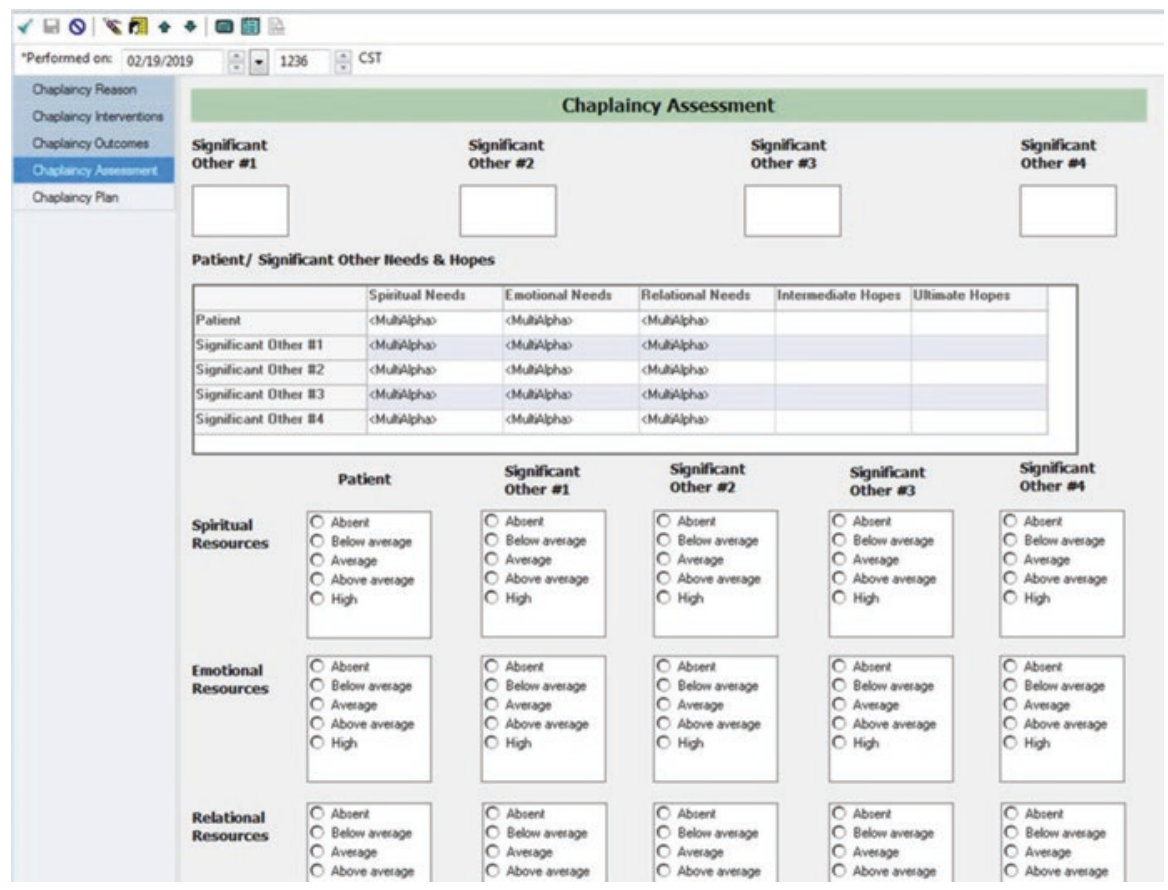

Fig. 5 Chaplaincy Assessment Form. (Reproduced with permission from Memorial Hermann Health System. Copyright @ 2013 Memorial Hermann. All rights reserved)

recipient mentions. Intermediate hopes are based in preferred outcomes (i.e., positive test result, restored function, cure, etc.). Ultimate hopes transcend any particular outcomes (i.e., trust in God, confidence in love and goodness, etc.) (VandeCreek and Lucas 2001, 14-15). Lester labeled these concepts as "finite" and "transfinite" hope (Lester 1995, 63-65) (Fig. 5).

The next portion of the assessment page enables the chaplain to evaluate the care recipient's spiritual, emotional, and relational resources. For each person, we can rate their resources in each category on a five-point scale from absent to high. If we rate all three categories of resources, a total resource score will appear in the appropriate box below. If we rate only one or two of the categories, our assessment of resources will be recorded without a total resource score (range of 1 to 15). The relative proportionality of needs, hopes, and resources is a key part of our assessment. High needs and hopes paired with limited resources could indicate greater need for chaplaincy care. Similarly high needs and hopes paired with strong resources likely indicate lower need for chaplaincy care. A caring, experienced, knowledgeable, and skilled chaplain is potentially a tremendous resource for others (Fig. 6).

The "Resources Identified" free text box allows us to specifically record any resources identified in our assessment. 


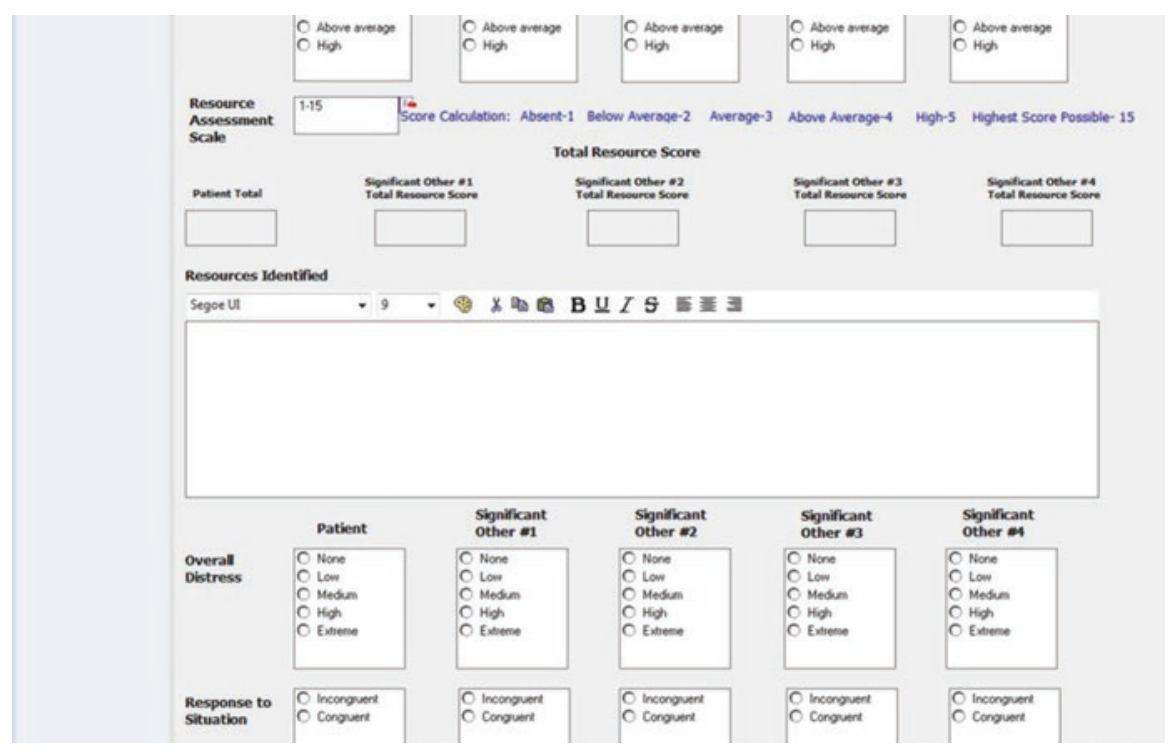

Fig. 6 Chaplaincy Assessment Form, Detail Resource Scale. (Reproduced with permission from Memorial Hermann Health System. Copyright (C) 2013 Memorial Hermann. All rights reserved)

The "Overall Distress" is a summary rating of the care recipient's suffering from none to extreme.

The "Response to Situation" has two choices. An "Incongruent" response is an indication the care recipient's overall distress is significantly higher or lower than what the chaplain has experienced from others in similar circumstances. Incongruence may be an indication of something that needs special chaplaincy attention and further assessment.

The "Subject Sated" free text box is used to record direct quotes from the care recipient relevant to the chaplaincy assessment (i.e., "I think I might be depressed" (Fig. 7)).

\subsection{Plan}

We indicate our plans for further care and recommendations to the interdisciplinary healthcare team on the plan page. The "Chaplaincy Plan" box contains four levels of our intent to follow up. Selecting "Will follow up" is an indication the care recipient definitely needs additional chaplaincy support. It also opens the "Follow up needed for" box in which the chaplain can indicate the areas of follow-up needs. Selecting "Follow up as circumstances allow" is an indication the care recipient could benefit from additional chaplaincy support if it can be arranged. Selecting 


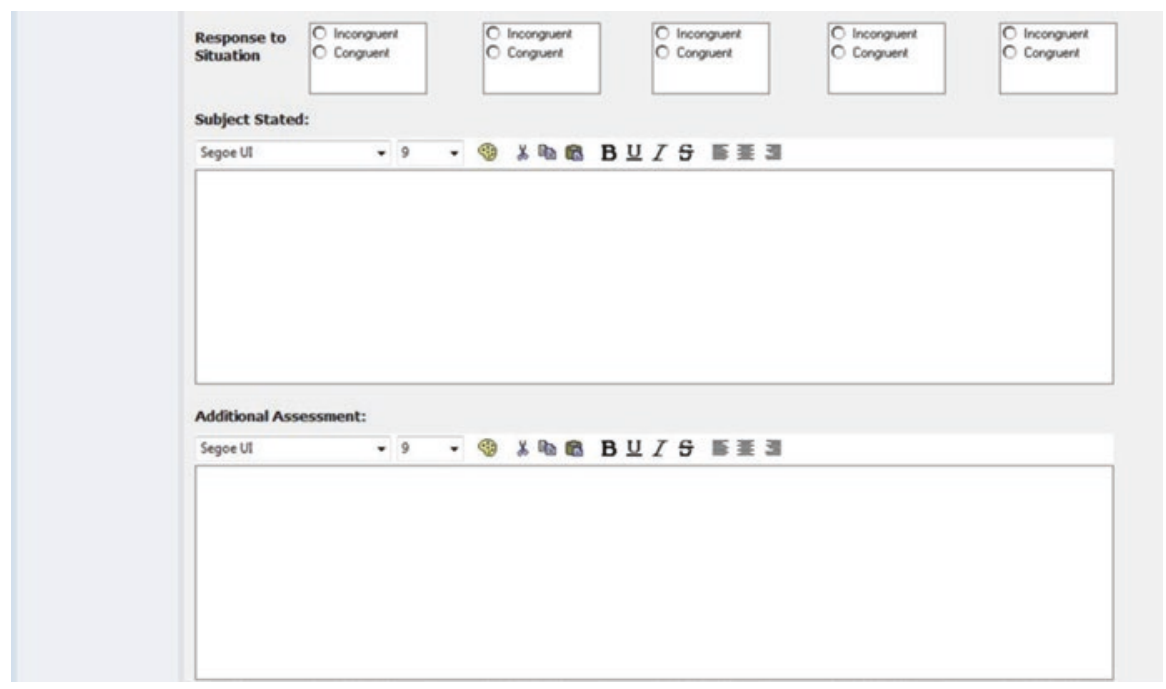

Fig. 7 Chaplaincy Assessment Form, Free Text Boxes. (Reproduced with permission from Memorial Hermann Health System. Copyright (C) 2013 Memorial Hermann. All rights reserved)

"Follow PRN" is an indication of no present need for additional chaplaincy support while acknowledging the situation is such that future needs may arise before discharge. Selecting "No follow up warranted at this time" is an indication there are no current or anticipated chaplaincy needs. Selecting "Will make referral to" opens the "Referral Needed to" box to indicate sources of referral help the chaplain will seek for the care recipient (Fig. 8).

\section{Sample Chart Note}

Our completed chart notes are more streamlined. They contain only the selected or typed content. All of the other items available in the extensive data input template are not imported into the final note. Below is an example of what one looks like.

Result type: Chaplaincy Note

Result date: 04/29/2018 11:22

Result status: Auth (Verified)

Result title: Chaplaincy Visit

Performed by: Chaplain, Charlie on 04/29/2018 11:22

Signed by: Chaplain, Charlie on 04/29/2018 11:22

Encounter info: HH HERMANN, Inpatient, 11/17/2017 -

\section{Final Report *}

Chaplaincy Visit Entered On: 04/29/2018 12:13

Performed On: 04/29/2018 11:22 by Chaplain, Charlie 


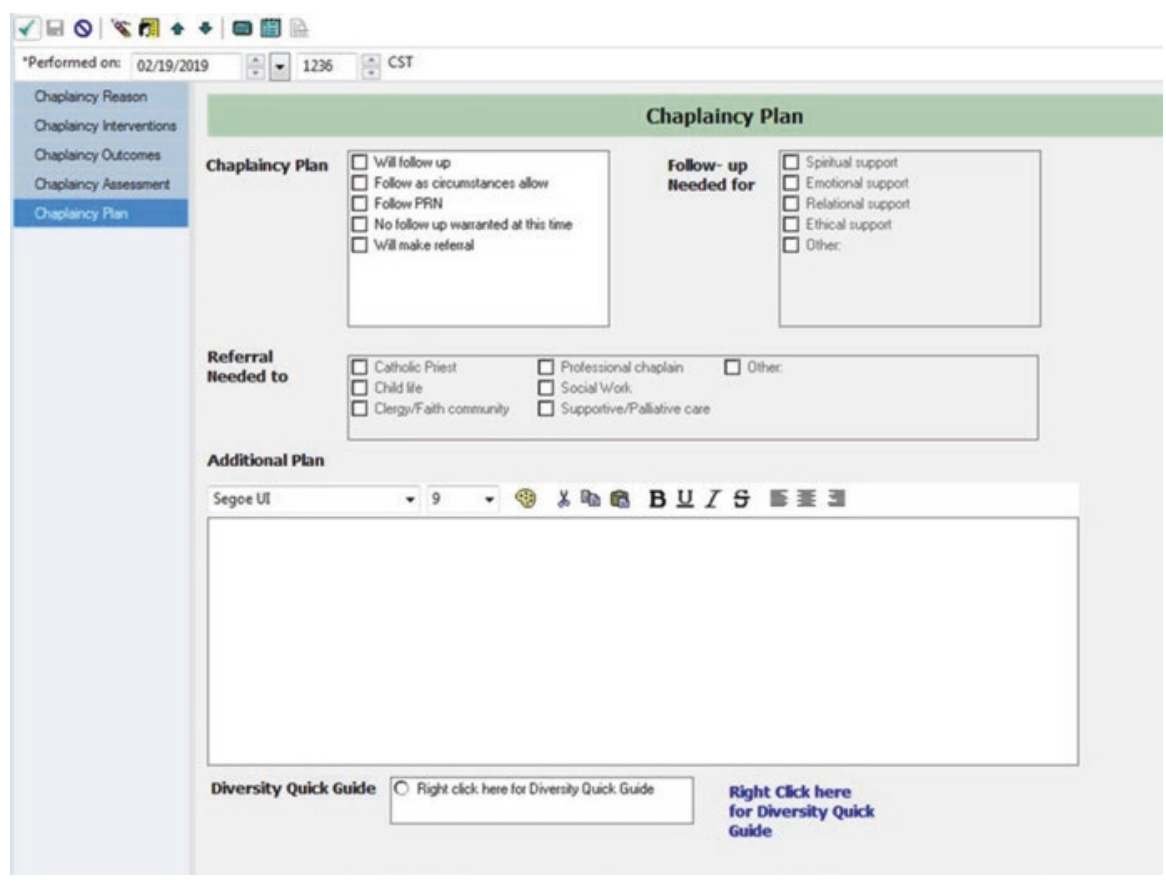

Fig. 8 Chaplaincy plan form. (Reproduced with permission from Memorial Hermann Health System. Copyright @ 2013 Memorial Hermann. All rights reserved(

\section{Chaplaincy Reason}

Chaplaincy Time Spent: 45

Chaplaincy Reason for Visit: Initial visit, Referral from, Rounds visit

Chaplain Referral Source: Nurse

CH Additional Visit Info: RN (Becky) told me Pt [abbreviation for "patient"] was "having a hard day" and asked for me to check on her.

CH Religious Preference: Methodist

\section{Chaplaincy Interventions}

Empowerment Interventions: Encouraged focus on present, Normalized experience of patient/family, Provided anticipatory guidance, Provided anxiety containment, Provided chaplaincy education, Provided education regarding spiritual practice(s)

Exploration Interventions: Explored emotional needs and resources, Explored hope, Explored relational needs and resources, Explored spiritual needs and resources, Facilitated storytelling, Identified, evaluated, and reinforced appropriate coping strategies

Collaboration Interventions: Consulted with interdisciplinary team, Encouraged adherence to treatment plan

Relationship Building Interventions: Cultivated a relationship of care and support, Listened empathetically 
Ritual Interventions: Provided prayer

Significant Other \#1 Title: husband

Empowerment Interventions SO1: Provided chaplaincy education

Significant Other \#2 Title: daughter

Significant Other \#3 Title: son-in-law

Significant Other \#4 Title: grandson

Additional Interventions: Provided instruction re meditative prayer as an anxiety containment strategy

\section{Chaplaincy Outcomes}

Patient Outcomes: Debriefed/defused experience, Distress reduced, Emotional resources utilized, Expressed gratitude, Expressed intermediate hope, Expressed ultimate hope, Progressed toward focus on present, Relational resources utilized, Spiritual resources utilized, Tearfully processed emotions, Verbally processed emotions

Significant Other \#1 Title: husband

Significant Other \#1 Outcomes: Unknown outcome

Significant Other \#2 Title: daughter

Significant Other \#3 Title: son-in-law

Significant Other \#4 Title: grandson

Chaplaincy Additional Outcomes: Pt shared her medical narrative. She identified and processed the spiritual and emotional sequelae. Reported anxiety decreased. Breathing slowed and became more regular. Pt smiled more.

\section{Chaplaincy Assessment}

Significant Other \#1 Title: husband Significant Other \#2 Title: daughter Significant Other \#3 Title: son-in-law Significant Other \#4 Title: grandson

Pt Spiritual Resources: Above average

Pt Emotional Resources: Average

Pt Relational Resources: Above average

SO1 Relational Resources: Above average

Resource Assessment Scale: 1-15

Pt Resource Score: 11

CH Helpful Resources Identified: Pt articulated strong, long-tenured, and supportive personal Christian faith. She seems emotionally strong and mature. She mentioned her husband, adult children, and faith community (Grace United Methodist in Pleasant Prairie) as sources of good relational support.

Patient Overall Distress: Medium

SO1 Overall Distress: Low

Patient Congruency Response: Congruent

SO1 Response: Congruent 
Subject Stated: Patient: "I know God will take care of me no matter what. He has brought me through so much. I am blessed!"

Additional Assessment: Husband left room after brief introduction. Pt mentioned normal mixed emotions re prospect of potentially curative brain surgery. She expressed moderate anxiety re unknown. She mentioned fears of not being a suitable surgical candidate and of possible lack of efficacy or of unintended consequences of surgery (lost function). She also expressed the strong desires to have the surgery and be sz [abbreviation for "seizure"] free for the first time in decades. Her anxiety seemed lessened after chaplaincy care. Per her report and chaplain's observations, she benefitted from chaplaincy support.

\section{Chaplaincy Plan}

Chaplaincy Follow- up: Will follow up, Will make referral

Follow-Up For: Spiritual support, Emotional support

Chaplain Referral To: Clergy/Faith community, Professional chaplain

Chaplaincy Additional Plan: Because Pt is scheduled for sleep deprivation tonight, will make referral to night chaplain (Allan Jenkins) for follow up. Per pt's request, will contact her pastor to request a hospital visit.

\section{Chaplaincy Screening Process}

In 2014 we implemented a new chaplaincy screening process in our EMR software. The purpose of this process is to identify patients/families with potential spiritual or religious struggle, as well as those who would like to receive chaplaincy support. After a thorough literature review and consulting with other healthcare organizations around the nation regarding best practice, we settled upon the Rush Protocol as the model for our screening process. It was originally developed by the chaplains at Rush University Medical Center in Chicago. At the time, it was the most thoroughly researched and validated screening tool for potential spiritual or religious struggle (cf. Fitchett and Risk 2009, 1-12, and see below for a diagram of the resulting Memorial Hermann Chaplaincy Screening Process). This screening process is a part of the nurse admission history completed in the EMR by a nurse caring for the patient/family. Patients/families are asked two to three questions (the number depends upon the answers they provide). A task is automatically generated in our department task list whenever a patient/family answers a question in a manner that indicates possible spiritual or religious struggle or when he/she requests chaplaincy support (Fig. 9). 


\section{Memorial Hermann Chaplaincy Screening Process}

Introductory statement:

Many patients and families have religious or spiritual beliefs that give them strength, comfort, and contribute to health.

1. As you cope with your condition/illness/injury, is religion or spirituality important to you?

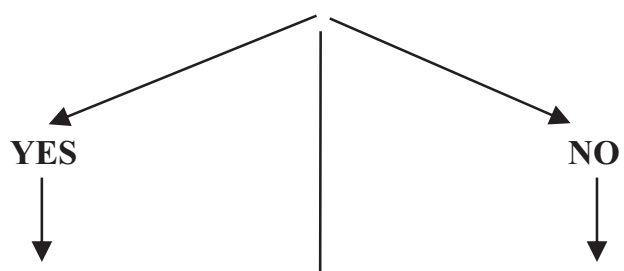

2. How much strength or comfort are you getting from religion or spirituality?

\section{A) all that you need}

\section{- For A, go to Question 3}

B) less than you need

C) none at all

For either $B$ or $C$, thank patient.

(automated chaplain referral)

3. Would you like to request spiritual or emotional support from a chaplain?

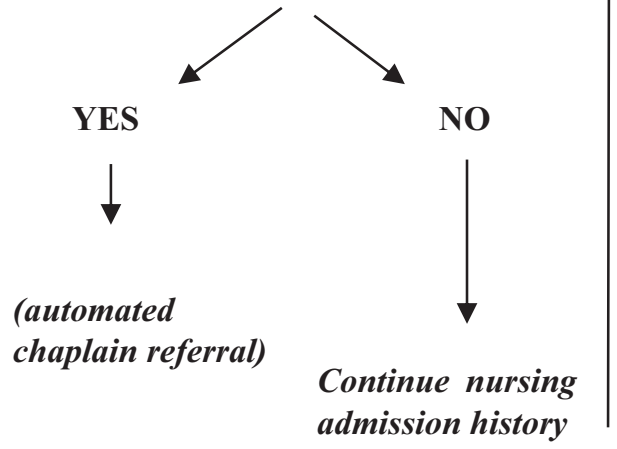

4. The chaplain may make rounds, would you like to request spiritual or emotional support from a chaplain?

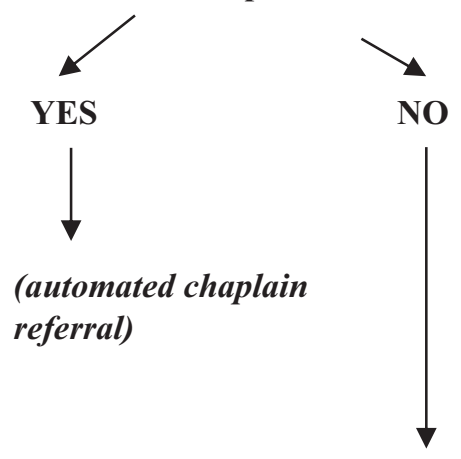

Continue nursing admission history

Fig. 9 Memorial Hermann Chaplaincy Screening Process (Adapted from The Rush Protocol in Fitchett and Risk 2009. Screening for spiritual struggle, with permission from SAGE Publications. JournalofPastoralCare \& Counseling63(1-2):1-12.https://doi.org/10.1177/154230500906300104; Copyright (c) 2009 SAGE Publications. All rights reserved) 


\section{Glossary}

\section{Interventions (44)}

Empowerment

- Clarified, confirmed, or reviewed information from treatment team - chaplain helps patient/family understand information related to patient's treatment plan.

Example: Chaplain assists spouse in recalling unfamiliar diagnostic term used by physician.

- Encouraged assertiveness - chaplain seeks to improve the care recipient's skills in expressing to others his/her concerns, thoughts, emotions, or rights.

Example: Chaplain encourages patient to voice to her physician her disagreement with her treatment plan.

- Encouraged focus on present - chaplain helps the care recipient to experience the benefits of attention to the present in contrast to inordinate or unhealthy focus on the past or future.

Example: Chaplain recognizes catastrophic thinking and anxiety about possible future events and suggests greater consideration of gifts and challenges of today.

- Encouraged self-care - chaplain encourages the care recipient to engage in basic activities that nourish and sustain spiritual, emotional, relational, and physical health.

Example: Chaplain learns that parent of patient has neither slept nor eaten in over 24 hours and recommends both.

- Facilitated completion of advance directive - chaplain helps the care recipient consider options and complete advance directive document(s).

Example: Chaplain helps patient evaluate and decide who among her family would make the best medical power of attorney for her.

- Facilitated group experience - chaplain leads a group meeting intended to contribute to the well-being of participants.

Example: Chaplain leads support group for brain cancer patients and families.

- Normalized experience of patient/family - chaplain reassures the care recipient that new and distressing reactions are common to others with similar experiences and not pathological.

Example: Husband says, "I'm losing my mind. I cannot remember anything the doctor told me about her condition." Chaplain responds, "Most people find it hard to think and remember under this kind of stress." 
- Provided anticipatory guidance - chaplain informs or makes recommendations to the care recipient about anticipated experiences.

Example: Chaplain describes common symptoms of approaching death to prevent distress among family gathered at terminal patient's bedside.

- Provided anxiety containment - chaplain helps the care recipient to strengthen their ability to respond constructively to unspecified threat(s).

Example: Chaplain guides patient's partner through progressive relaxation exercise.

- Provided chaplaincy education - chaplain gives the care recipient information about how professional chaplains can help or how to access chaplaincy support.

Example: Chaplain explains, "Chaplains are here for spiritual and emotional support for patients and families from diverse faith perspectives or no particular faith perspective."

- Provided grief counseling - chaplain helps the care recipient heal from the pain of loss.

Example: Chaplain listens empathically to son's painful account of all he will miss after his mother's death.

- Provided guilt counseling - chaplain helps the care recipient understand and respond beneficially to emotions of guilt or shame.

Example: Chaplain helps patient identify ways he can realign his behavior with his personal values.

- Provided education regarding spiritual practice(s) - chaplain teaches the care recipient beneficial spiritual practices.

Example: Chaplain teaches patient a meditative prayer technique to aid in pain management.

- Reframed experience of patient/family - chaplain helps the care recipient consider his/her experience from a different and potentially more beneficial perspective.

Example: Chaplain reflects, "I wonder if it was simply an oversight born of distraction?" in response to a description of another's offensive behavior.

\section{Exploration}

- Explored alternatives - chaplain helps the care recipient carefully consider his/ her options.

Example: Chaplain leads patient to verbalize treatment alternatives along with the pros and cons of each. 
- Explored emotional needs and resources - chaplain helps the care recipient identify, evaluate, or gain insight into his/her emotions along with their current and potential contributions to his/her well-being.

Example: Chaplain helps father identify the hurt and fear that underlies his expressed anger.

- Explored hope - chaplain helps the care recipient identify, understand, or rely upon sources of intermediate and ultimate hope.

Example: Spouse says, "We haven't lost hope." Chaplain asks, "Upon what or whom does your hope rest?"

- Explored relational needs and resources - chaplain helps the care recipient identify, evaluate, or gain insight into his/her relationships along with their current and potential contributions to his/her well-being.

Example: Chaplain helps patient to reflect upon parameters of control and trust in her significant relationships to achieve healthy equilibrium.

- Explored spiritual needs and resources - chaplain helps the care recipient identify, evaluate, or gain insight into his/her meaningful connections. ${ }^{5}$

Example: Chaplain listens attentively and reflectively as patient shares his beliefs and the strength they provide.

- Facilitated expression of regret - chaplain provides a safe space for the care recipient to express regret over his/her thoughts, words, actions, or failure to act.

Example: Chaplain carefully listens as a teenage patient confesses the recent mistakes she has made.

- Facilitated life review - chaplain helps the care recipient tell stories from his/ her life to bring forth beneficial actions or attitudes.

Example: Chaplain asks a patient with terminal illness, "What relationships have meant the most to you through the years?"

- Facilitated storytelling - chaplain helps the care recipient communicate his/her medical or life narrative.

Example: Chaplain asks, "How did you end up here in the hospital?"

- Identified, evaluated, and reinforced appropriate coping strategies - chaplain elicits from the care recipient his/her strategies for confronting personal challenges and assesses their helpfulness.

\footnotetext{
5 "Spirituality is the aspect of humanity that refers to the way individuals seek and express meaning and purpose and the way they experience their connectedness to the moment, to self, to others, to nature, and to the significant or sacred" (Puchalski et al. 2009, 885-904).
} 
Example: Chaplain asks, "Have you identified anything that has helped you deal with anxiety in the past?"

\section{Collaboration}

- Advocated for patient/family - chaplain speaks, writes, or acts on behalf of the care recipient's needs, especially when institutional or authority structures have not satisfactorily addressed those needs.

Example: Chaplain appeals to another healthcare professional to alter patient's treatment plan to accommodate patient/family spiritual, emotional, and/or relational needs.

- Consulted with interdisciplinary team - chaplain consults with other healthcare professional(s) to acquire or provide information intended to optimize care for patient/family.

Example: Chaplain participates in multidisciplinary rounds meeting.

- Encouraged adherence to treatment plan - chaplain encourages the care recipient to engage suggested activity or inactivity prescribed by treatment team.

Example: Chaplain affirms to a severely depressed patient the value of regularly taking his psycho-pharmaceutical medications.

Facilitated respect for spiritual/cultural practice during hospitalization - chaplain helps the care recipient maintain meaningful practice while in the hospital.

Example: Chaplain arranges for halal diet for Muslim patient.

Relationship Building

- Cultivated a relationship of care and support - chaplain introduces self and begins to establish a caring relationship through which the care recipient is helped.

Example: "Hello, Mr. Simpson, I am Chaplain Mary. I stopped by to see how you are doing today."

- Facilitated reconciliation with faith community - chaplain helps the care recipient resolve estrangement from his/her faith community.

Example: Upon hearing patient's grief from having "drifted away" from his synagogue, with patient's permission, chaplain calls rabbi to arrange visit at hospital.

- Facilitated reconciliation with significant others - chaplain helps the care recipient restore human relationships damaged by past action, misunderstanding, or neglect.

Example: Chaplain coaches dying patient through a process of apologizing to his children for past neglect. 
- Facilitated reconciliation with the transcendent - chaplain helps the care recipient restore a transcendent relationship damaged by past action, misunderstanding, or neglect.

Example: Chaplain helps sister of patient seek forgiveness from and express love to God.

- Listened empathically - chaplain listens in a manner that conveys to the care recipient cognitive and affective perception and understanding of the care recipient's experience.

Example: Chaplain says, "This sounds like it has been extremely difficult for you."

- Mediated conflict - chaplain helps care recipients to de-escalate or resolve conflict.

Example: After vocal disagreement between ICU patient's ex-wives, chaplain helps family agree upon visitation schedule acceptable to all.

- Provided hospitality - chaplain helps the care recipient through small acts of service.

Example: Chaplain provides ice water and coffee for family as they await an update about their loved one's surgery.

- Provided relationship counseling - chaplain helps the care recipient experience more satisfying relationships.

Example: Chaplain suggests a strategy for parenting a toddler.

- Provided silent and supportive presence - chaplain accompanies the care recipient while nonverbally communicating empathy and support.

Example: Chaplain gently touches a bereaved husband's shoulder and supplies tissue as he weeps over his wife's death.

$\underline{\text { Ritual }}$

- Celebrated with patient/family - chaplain joins the other in expressing positive emotions resulting from a preferred circumstance.

Example: Chaplain rejoices with patient/family about a positive medical test result.

- Facilitated postmortem needs/rituals - chaplain helps the care recipient care for the body of loved one according to his/her beliefs.

Example: Chaplain arranges for Buddhist priest to perform postmortem ritual for deceased patient and insures with healthcare team that the body will remain undisturbed for 8 hours.

- Priest provided sacrament of the sick - Roman Catholic priest provides sacrament of the sick (often referred to by outdated term "last rites") for care recipient. 
Example: Chaplain arranges for family's priest to provide sacrament of the sick.

- Provided baptism - chaplain performs rite of Christian baptism for care recipient.

Example: Chaplain baptizes terminally ill infant.

- Provided prayer - chaplain prays (aloud, silently, with others, or alone) for the care recipient according to the care recipient's preference and faith tradition.

Example: Chaplain joins a Roman Catholic family in reciting the "Our Father."

- Provided religious resources - chaplain supplies literature, objects, or personnel intended to facilitate the care recipient's religious practice.

Example: Chaplain provides flameless candles for Jewish family Sabbath ceremony.

- Provided ritual - chaplain supplies rite or ceremony meaningful to the care recipient.

Example: Chaplain conducts naming and blessing ceremony for parents of stillborn child.

- Read sacred text - chaplain reads aloud written material revered by the care recipient.

Example: Chaplain reads a Psalm at patient's bedside.

\section{Outcomes (32)}

- Arranged for community clergy surrogate - after confirming that patient meets the criteria ${ }^{6}$ for a clergy surrogate decision maker, chaplain enlists clergy surrogate.

Example: Chaplain reviews patients' medical record, consults with treatment team, identifies clergy surrogate, and facilitates communication between surrogate and physician.

- Catharsis - a sudden expression of previously restrained emotions resulting in a reduction of distress

Example: Patient angrily shares a litany of complaints about her hospital experience which culminates in a fit of sobbing and concludes with "I feel better."

- Debriefed/defused experience - an oral recounting of events and associated reactions, often resulting in decreased emotional tension and/or clarified cognition.

Example: Mother tells the story of the automobile accident that resulted in her child's hospitalization.

\footnotetext{
${ }^{6}$ Texas Health and Safety Code Chap. 313: Consent to Medical Treatment Act
} 
- Declined chaplain support - choosing not to receive chaplaincy care.

Example: After chaplain introduction, patient's husband says, "We're all fine here. But, thanks for stopping by."

- Developed chaplaincy care plan - chaplain and care recipient collaborate to identify desired chaplaincy outcomes and anticipated interventions intended to realize them.

Example: Chaplain and patient with an intrauterine fetal demise agree on a plan for a naming and blessing ceremony after she delivers her baby.

- Distress reduced - unpleasant or disturbing emotions are decreased.

Example: Patient's primary facial expression transitions from fearful to happy.

- Emotional resources utilized - care recipient is able to make use of sources of inner emotional strength to cope with present needs.

Example: Patient draws upon her athletic experience and learned ability to delay gratification in order to avoid discouragement in physical therapy.

- Expressed gratitude - care recipient communicates thankfulness.

Example: Son mentions thanks that his mother's cancer was discovered before metastasis.

- Expressed humor - care recipient employs humor.

Example: Family mixes funny accounts from his life with their tears around patient's deathbed.

- Expressed intermediate hope - care recipient articulates hope based on preferred future outcomes.

Example: Patient mentions her desire to regain enough agility to be able to play on the floor with her grandchildren.

- Expressed peace - care recipient communicates intrapersonal and/or interpersonal serenity.

Example: Patient describes a lack of inner conflict about his chosen treatment plan.

- Expressed ultimate hope - care recipient articulates hope not based on preferred future outcomes.

Example: Daughter states, "I would rather my father is able to live a few more years. But, whether he lives or dies, I know he will be safe in God's loving care."

- Identified meaningful connections - care recipient names relationships with persons, places, activities, or ideas that provide meaning and/or purpose.

Example: Patient discusses how much she values three lifelong friends. 
- Identified priorities - care recipient describes what is of greatest importance.

Example: Patient expresses his preference to remain alert and able to communicate over complete pain control.

- Improved communication - care recipients are able to more clearly exchange messages.

Example: Mother and physician are each better able to understand each other's perspective.

- Made decisions - care recipient decides among alternatives.

Example: Patient chooses among possible discharge options.

- Progressed toward acceptance - care recipient moves toward acquiescence of unwanted realities.

Example: Paraplegic is able to acknowledge a meaningful life without walking.

- Progressed toward adherence - care recipient increasingly follows his/her medical treatment plan.

Example: Depressed patient agrees to attend weekly psychotherapy sessions and take antidepressant medication.

- Progressed toward autonomy - care recipient moves toward freedom and self-governance.

Example: Abused wife makes a plan to seek the assistance of a local women's shelter after discharge from hospital.

- Progressed toward equilibrium of responsibility and trust - care recipient is more able to take appropriate personal responsibility while trusting others to fulfill their responsibilities.

Example: Mother is able to acknowledge both that she took reasonable precautions to ensure her child's safety and another's carelessness caused his hospitalization.

- Progressed toward focus on present - care recipient increasingly experiences the benefits of attention to the present in contrast to inordinate, or unhealthy, focus on the past or future.

Example: Patient is able to self-correct when his thoughts and conversations are focused too much on the past or future.

- Progressed toward meaning - care recipient is better able to identify and describe significance.

Example: Patient states, "I guess my suffering was meant to help me slow down and love more." 
- Progressed toward new normal - care recipient increasingly accepts new circumstances and finds satisfying ways to live within them.

Example: Paraplegic patient joins and enjoys a wheelchair basketball league.

- Progressed toward purpose - care recipient is better able to identify and describe desired ends or consequences from his/her life.

Example: Patient comments, "I want to be remembered as a decent man who loved people, especially my family and friends."

- Progressed toward reconciliation - care recipient experiences a reduction in relational conflict or estrangement.

Example: Patient's daughter decides to call her brother to whom she has not spoken in several years.

- Progressed toward understanding - care recipient more clearly perceives reality.

Example: Wife articulates accurately her husband's condition, prognosis, and treatment plan.

- Relational resources utilized - care recipient is able to make use of social support network to cope with present needs.

Example: Mother of patient accepts neighbor's offer to care for her other children.

- Reported decreased pain - care recipient communicates lessened spiritual, emotional, relational, or physical pain.

Example: After expressing secret feelings of guilt patient states, "It feels good to get that off my chest."

- Spiritual resources utilized - care recipient is able to make use of sources of spiritual strength to cope with present needs.

Example: Patient expresses verbally and nonverbally confidence in the care of a loving higher power.

- Tearfully processed emotions - care recipient expresses emotions through the means of tears.

Example: Father intensely sobs as he holds the body of his stillborn baby.

- Unknown outcome - chaplaincy care produced unidentified results.

Example: Dementia patient communicates no discernible reaction to chaplaincy interventions.

- Verbally processed emotions - care recipient expresses emotions through the means of words.

Example: Trauma patient talks through her feelings about the drunken driver that caused injury to her and her family. 


\section{Commentary}

\section{Simon Peng-Keller}

\section{A Milestone in Digital Recording Spiritual Care}

In order to understand why practices of recording spiritual care in EMR have been gaining currency in recent years, it is helpful to study paradigmatic cases. Brent Peery offers not only an illuminating example but also a model of best practice. It is taken from of an institution which has an extraordinarily long history of chaplaincy records. The chapter can be seen as an exercise in affirmative genealogy: By telling the history of the current practice in the Memorial Hermann Health System in Houston, Peery explains which considerations, experiences, and decisions are behind it - historically as well as structurally. One might put the chapter's main thesis as follows: In order to offer the best possible spiritual care in the context of the constraints of current health systems, chaplains have a double task: first, they are required to develop a recording tool suitable for spiritual care in the framework of a specific institution; second, they need to train themselves in the use of the tool to record their work. Beyond any doubt, digital charting changes the daily practice of healthcare chaplains considerably. Charting is not only time-consuming: it implies restructuring one's work, framing one's perceptions, modifying one's communication. Peery doesn't ignore the challenges, but he emphasizes the advantages of this development. In my commentary I will focus, first, on the conceptual framework of the model described. In particular, I examine its relationship to the paradigm of outcome-oriented chaplaincy. With regard to possible implementations of the model, I analyze, second, the information provided by the chapter about the tool and the practice of recording in the Memorial Hermann Health System.

\section{Recording Outcome-Oriented Chaplaincy}

Three factors explain why recording spiritual care in the Memorial Hermann Health System has taken the elaborated form described in Peery's chapter: the long tradition of charting chaplaincy in medical records, the more recent emergence of EMR, and, not least, the paradigm of outcome-oriented chaplaincy. As we outline in the introduction, the latter was developed by Art Lucas in the 1990s at Barnes Jewish Hospital in Saint Louis, Missouri. Lucas was dissatisfied with the standard paradigm of Clinical Pastoral Education centered in recent decades on unintentional presence. His vision was to improve spiritual care by developing and implementing a more structured and more disciplined approach, influenced probably by his Methodist background. When planning this volume and inviting the contributors, we didn't realize that two of them were so deeply influenced by Lucas (cf. the contribution of Anne Vandenhoeck). This may not be a mere coincidence. There is a mutual affinity between this new paradigm of healthcare chaplaincy and the emergence of the EMR which provides a technical structure for the former. What Lucas developed with ink and paper fits perfectly with the new world of digital health. In the following, I shall consider this mutual affinity with regard to the paradigm case of Memorial Hermann.

The traces of Lucas are to be found on different levels. First of all, the structure is clearly outcome-oriented. Clear objectives and procedures are at stake: assessment, plan, intervention, outcomes. The MH model does not merely reflect a very structured process of spiritual care, rather it compels chaplains to structure their work in a predetermined manner. Peery states it clearly: "The MH chaplaincy documentation model is a communication strategy." Lucas's influence is also reflected in key concepts, even though some of them are also used elsewhere (e.g., the difference between intermediate and ultimate hope). Finally, the signature of the outcome-oriented paradigm is to be seen in the computing of "overall distress," a procedure for measuring the emergency (cf. Figure 6).

The MH chaplaincy documentation model may give rise to at least two sorts of qualms. The first has to do with language, the second with structure. Is the language used suitable for the practice it is supposed to describe and orientate? Or asked more pointedly: Are the outcomes of outcome-oriented language in line with the objectives of chaplaincy itself? Is 
it compatible with a spirituality which is formed by the logic of an unfathomable gift, not primarily by plans, goals, and success? It can hardly be denied: As language creates reality and as digital instruments (and their realities) form today's clinical practice, the concepts and tools for describing spiritual care have remarkable outcomes themselves. One could relativize the objection with the hint that the administrative language is to be found mainly on the level of the super-categories (assessment, plan, interventions, outcomes), while the subcategories remain the traditional ones (prayer, anointment of the sick, etc.). This may be one of the compromises necessary for interprofessional communication. Nevertheless, I cannot help but consider it a misclassification to subsume prayer under intervention.

The qualms with structure are connected to the question of the power of medical and administrative language. In counterbalancing those approaches to chaplaincy that overemphasize unintentional presence, Lucas provides an important inspiration for the development of spiritual care. My concern here is over-structuring, a problem inherent in all models and tools of documentation. In our workshop Brent Peery argued convincingly that through good training and experience chaplains may attain the ability to use the digital tool in a flexible manner. For the further development of chaplaincy worldwide, it would be useful to document such individual learning processes in recording spiritual care!

\section{The Core of Spiritual Care?}

A lot of training and experience is required to master a fine-grained digital tool for recording spiritual care. Only healthcare chaplains working with it permanently are able to acquire the skills and the habits needed. This ability, then, will separate board-certified healthcare chaplains from visiting ministers on the one hand and healthcare professionals on the other hand. It is supposed to facilitate interprofessional communication. But what role is to be played by physicians, nurses, and other care-givers in the interprofessional spiritual care epitomized by this tool? (Considering this aspect of the MH model, Michael and Tracy Balboni's critical remark came to my mind: "that professionalization of chaplains will undermine the role of [...] medical professionals in offering spiritual care" [Hostility to Hospitality. Spirituality and Professional Socialization within Medicine, Oxford 2019, 252-253]. I doubt, however, that the professionalization of healthcare chaplaincy must have the effect of diminishing the spiritual care specific to physicians, nurses, and other caregivers.) Are they to be mere readers? Or do they have their own tools for recording the spiritual care that forms part of their professional activities?

Learning to chart is becoming part of the basic training for healthcare chaplaincy, part of the process of its ongoing professionalization. The 44 interventions listed in the glossary are very revealing as to what these professionals are up to do besides charting. I read the list carefully against the background of my own experiences as a part-time chaplain in a palliative care unit. Most of the activities listed are part of my work and that of my colleagues. (Some further activities could be added, for example, singing or humming religious and nonreligious songs.) But it is the first time I have seen them listed in such a complete and orderly fashion. Without any doubt, well-structured tools for recording spiritual care foster reflection and awareness. Considering the entries, one might conclude that the main focus of a chaplain's work lays on psychosocial support. Most of the "interventions" could also be provided by a psychologist. The old question of the Clinical Pastoral Education, the relationship between pastoral and psychological counseling, reemerges here. Strikingly, psychologists are missing from the list of other professions eligible for referrals (cf. Figure 8).

\section{Final Thoughts}

What impressed me most when I became acquainted with MH's digital tool was its elasticity and user-friendliness. Chaplains have enough space for longer narrative entries, but they can confine themselves to a few clicks as well. In each case, the computer will summarize all entries neatly and calculate, if possible, the total distress. Developed by what Peery calls the "Comprehensive School," the tool could also be useful for partisans of the "Minimalist School" or other schools. With this remarkable offspring of years of intensive work and experience, Brent Peery and his colleagues have set a milestone in the development of the charting of spiritual care in EMR. 


\section{References}

Association for Clinical Pastoral Education, Association of Professional Chaplains, Canadian Association for Spiritual Care, National Association of Catholic Chaplains, and Neshama: Association of Jewish Chaplains. 2016. Common qualifications and competencies for professional chaplains.

Association of Professional Chaplains Committee on Quality. 2015. Standards of practice for professional chaplains. Accessed on 2/15/19 at http://www.professionalchaplains.org/Files/ professional_standards/standards_of_practice/Standards_of_Practice_for_Professional_ Chaplains_102215.pdf.

Cadge, Wendy. 2012. Paging god: Religion in the halls of medicine. Chicago: The University of Chicago Press.

Comprehensive. n.d. Collins English dictionary - complete \& unabridged 10th edition. Retrieved February 20, 2016 from Dictionary.com website http://dictionary.reference.com/browse/ comprehensive.

Dicks, Russell. 1940. Standards for the work of the chaplain in the general hospital. Hospitals November.

Fitchett, George, and James Risk. 2009. Screening for spiritual struggle. The Journal of Pastoral Care \& Counseling 63: 12.

Hilsman, Gordon. 2017. Spiritual care in common terms: How chaplains can effectively describe the spiritual needs of patients in medical records. Philadelphia: Jessica Kingsley Publishers.

Lester, Andrew. 1995. Hope in pastoral care and counseling, 63-65. Louisville: Westminster John Knox Press.

Minimal. n.d. Collins English dictionary - Complete \& Unabridged 10th Edition. Retrieved February 20, 2016 from Dictionary.com website http://dictionary.reference.com/browse/ minimal.

Peery, Brent. 2008. Chaplaincy charting: One healthcare system's model. PlainViews 5:8. May 21. 2012a. Describing our magic. PlainViews 9:18. October 17.

. 2012b. Outcome oriented chaplaincy: Intentional caring. In Professional spiritual and pastoral care: A practical clergy and chaplain's handbook, ed. S. Roberts, 342-361. Woodstock: SkyLight Paths Publishing.

Puchalski, Christina, et al. 2009. Improving the quality of spiritual care as a dimension of palliative care: The report of the consensus conference. Journal of Palliative Medicine 12 (10): 885-904.

Texas Health and Safety Code Chapter 313: Consent to Medical Treatment Act.

VandeCreek, Larry, and Art Lucas, eds. 2001. The discipline for pastoral care giving: Foundations for outcome oriented chaplaincy. Binghamton: The Haworth Press.

Open Access This chapter is licensed under the terms of the Creative Commons Attribution 4.0 International License (http://creativecommons.org/licenses/by/4.0/), which permits use, sharing, adaptation, distribution and reproduction in any medium or format, as long as you give appropriate credit to the original author(s) and the source, provide a link to the Creative Commons license and indicate if changes were made.

The images or other third party material in this chapter are included in the chapter's Creative Commons license, unless indicated otherwise in a credit line to the material. If material is not included in the chapter's Creative Commons license and your intended use is not permitted by statutory regulation or exceeds the permitted use, you will need to obtain permission directly from the copyright holder.

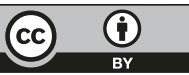

